
Glacial Periods

F. Lamy et al.

Science 343, 403 (2014);

DOI: $10.1126 /$ science. 1245424

This copy is for your personal, non-commercial use only.

If you wish to distribute this article to others, you can order high-quality copies for your

colleagues, clients, or customers by clicking here.

Permission to republish or repurpose articles or portions of articles can be obtained by following the guidelines here.

The following resources related to this article are available online at www.sciencemag.org (this information is current as of January 23, 2014 ):

Updated information and services, including high-resolution figures, can be found in the online version of this article at:

http://www.sciencemag.org/content/343/6169/403.full.html

Supporting Online Material can be found at:

http://www.sciencemag.org/content/suppl/2014/01/23/343.6169.403.DC1.html

This article cites 56 articles, 4 of which can be accessed free:

http://www.sciencemag.org/content/343/6169/403.full.html\#ref-list-1

This article appears in the following subject collections:

Atmospheric Science

http://www.sciencemag.org/cgi/collection/atmos 
correlates with the deepest part of the sedimentary basin.

The predicted ground motion is qualitatively similar for the VEA and CyberShake simulations (figs. S4 and S5); however, there are substantial quantitative differences in the level and distribution of the shaking (Fig. 4). SAVELA results show stronger shaking than CyberShake at most sites. This is especially true for receivers in the basin. We note that both methods are subject to substantial uncertainties. The accuracy of the CyberShake simulations depends strongly on the accuracy of the assumed crustal velocity model and its derived Green's functions. The accuracy of the virtual earthquake results depends strongly both on the accuracy of the ambient-field Green's functions and on the accuracy of the amplitude calibration. The Green's functions we used for this study (fig. S1) would be more accurate if we had data from a longer deployment. To estimate the variability in PGV due to the amplitude calibration described above, we measure the maximum difference in predicted PGV when using the calibration from either the Hector Road or Chino Hills earthquake to the mean of the calibration used in this study. The variability that results is bounded at $10 \mathrm{~cm} / \mathrm{s}$ for our simulations. For both the virtual earthquake and CyberShake simulations, the variation of the PGV is narrow for stations with low PGV values (bedrock sites) and wide for stations with high PGV values (basin sites). The coefficient of variation is approximately constant for SAVELA (fig. S7), which indicates that variability increases proportionally with ground motion amplitude.

Nonlinear effects in shallow materials are important in strong ground motion. Ground motion simulations that have incorporated nonlinear soil effects (29) have found a large decrease in the predicted strong ground motion. This could be an important effect for the scenarios we consider because unconsolidated sediments are likely to be found in sedimentary basins and would be expected to behave nonlinearly during strong shaking. We calibrated the amplitudes of the Green's functions, such that the peak amplitudes predicted by our approach matched those of moderatesized earthquakes. Our approach, as well as the CyberShake simulations, is based on an assumption of linearity. To the extent that nonlinear effects are important, our predicted ground motion amplitudes are likely to overestimate true amplitudes in future large earthquakes.

We confirm the presence and the influence of a waveguide to the west of San Gorgonio Pass that funnels seismic waves from San Andreas fault events into the Los Angeles Basin. This amplification is present for all tested scenarios. We also confirm that directivity couples with shallow crustal structure to increase basin amplification (6). We find a constant coefficient of variation, which means that shaking variability is proportional to shaking intensity. We also find a wider range of predicted peak amplitudes than is found in simulations, which would increase uncertainty in ground motion predictions and thereby impact seismic hazard assessments. We note, however, that there are substantial uncertainties in our estimated Green's functions and their amplitude calibration. Moreover, station coverage in the basin is sparse, and we have only sampled a small portion of the variability expected for a complex wavefield in the basin. Our results support more ambitious, targeted experiments to improve the accuracy of long-period strong ground motion prediction for future earthquakes in regions subject to high seismic risk.

\section{References and Notes}

1. P.-Y. Bard, M. Campillo, F. J. Chávez-Garcia, F. J. Sánchez-Sesma, Earthq. Spectra 4, 609-633 (1988)

2. K. B. Olsen, R. J. Archuleta, J. R. Matarese, Science 270, 1628-1632 (1995)

3. K. Olsen et al., Geophys. Res. Lett. 33, L07305 (2006).

4. K. B. Olsen et al., Geophys. Res. Lett. 36, L04303 (2009).

5. K. B. Olsen, Bull. Seismol. Soc. Am. 90 (6B), S77-S94 (2000).

6. R. Graves et al., Pure Appl. Geophys. 168, 367-381 (2011)

7. S. M. Day, D. Roten, K. B. Olsen, Geophys. J. Int. 189 1103-1124 (2012).

8. K. Aki, Bull. Earthq. Res. I. Tokyo 35, 415 (1957)

9. J. Claerbout, Geophysics 33, 264-269 (1968).

10. O. I. Lobkis, R. L. Weaver, J. Acoust. Soc. Am. 110, 3011 (2001).

11. R. L. Weaver, O. I. Lobkis, Geophysics 71, S15 (2006).

12. F. J. Sánchez-Sesma, M. Campillo, Bull. Seismol. Soc. Am. 96, 1182-1191 (2006)

13. M. Campillo, A. Paul, Science 299, 547-549 (2003)

14. N. M. Shapiro, M. Campillo, Geophys. Res. Lett. 31, L07614 (2004).

15. K. G. Sabra, P. Gerstoft, P. Roux, W. A. Kuperman, M. C. Fehler, Geophys. Res. Lett. 32, L03310 (2005).
16. N. M. Shapiro, M. Campillo, L. Stehly, M. H. Ritzwoller, Science 307, 1615-1618 (2005).

17. K. Nishida, H. Kawakatsu, K. Obara, J. Geophys. Res. 113 (B10), B10302 (2008).

18. G. A. Prieto, ]. F. Lawrence, G. C. Beroza, ]. Geophys. Res. 114 (B7), B07303 (2009).

19. G. A. Prieto, M. Denolle, ]. F. Lawrence, G. C. Beroza, C. R. Geosci. 343, 600-614 (2011).

20. G. A. Prieto, G. C. Beroza, Geophys. Res. Lett. 35, L14304 (2008)

21. M. A. Denolle, E. M. Dunham, G. A. Prieto, G. C. Beroza, J. Geophys. Res. 118, 2102 (2013).

22. R. Burridge, L. Knopoff, Bull. Seismol. Soc. Am. 54, 1875-1888 (1964).

23. H. Magistrale, S. Day, R. W. Clayton, R. Graves, Bull. Seismol. Soc. Am. 90 (6B), S65-S76 (2000).

24. M. D. Kohler, H. Magistrale, R. W. Clayton, Bull. Seismol. Soc. Am. 93, 757-774 (2003).

25. M. A. Denolle, E. M. Dunham, G. C. Beroza, Bull. Seismol. Soc. Am. 102, 1214-1223 (2012).

26. L. Stehly, M. Campillo, N. Shapiro, J. Geophys. Res. 111 (B10), B10306 (2006)

27. M. Guatteri, P. M. Mai, G. C. Beroza, Bull. Seismol. Soc. Am. 94, 2051-2063 (2004)

28. K. W. Campbell, Y. Bozorgnia, Bull. Seismol. Soc. Am. $\mathbf{9 3}$, 314-331 (2003).

29. D. Roten, K. B. Olsen, J. C. Pechmann, Bull. Seismol. Soc. Am. 102, 2008-2030 (2012).

Acknowledgments: We thank K. Olsen and anonymous reviewers for their comments and contributions to improve the manuscript. This work was supported by NSF grant EAR-0943885 and by the Southern California Earthquake Center (SCEC). SCEC is funded by NSF cooperative agreement EAR-0529922 and U.S. Geological Survey cooperative agreement 07HQAG0008. The SCEC contribution number for this paper is 1812. Data are available in the supplementary materials.

\section{Supplementary Materials}

www.sciencemag.org/content/343/6169/399/supp//DC1

Materials and Methods

Figs. S1 to $\mathrm{S7}$

References (30-33)

9 September 2013; accepted 19 December 2013

10.1126/science.1245678

\title{
Increased Dust Deposition in the Pacific Southern Ocean During Glacial Periods
}

\author{
F. Lamy,$^{1,2 *}$ R. Gersonde, ${ }^{1,2}$ G. Winckler,${ }^{3,4}$ 0. Esper, ${ }^{1}$ A. Jaeschke, ${ }^{1,2}$ G. Kuhn, ${ }^{1}$ ]. Ullermann, ${ }^{1}$ \\ A. Martinez-Garcia, ${ }^{5}$ F. Lambert, ${ }^{6}$ R. Kilian $^{7}$
}

Dust deposition in the Southern Ocean constitutes a critical modulator of past global climate variability, but how it has varied temporally and geographically is underdetermined. Here, we present data sets of glacial-interglacial dust-supply cycles from the largest Southern Ocean sector, the polar South Pacific, indicating three times higher dust deposition during glacial periods than during interglacials for the past million years. Although the most likely dust source for the South Pacific is Australia and New Zealand, the glacial-interglacial pattern and timing of lithogenic sediment deposition is similar to dust records from Antarctica and the South Atlantic dominated by Patagonian sources. These similarities imply large-scale common climate forcings, such as latitudinal shifts of the southern westerlies and regionally enhanced glaciogenic dust mobilization in New Zealand and Patagonia.

ineral aerosols (dust) play a crucial role in determining the pattern and magnitude of climate variability. Dust im- purities trapped in Antarctic ice point to $\sim 25$ times higher glacial dust fluxes compared with interglacials $(1)$. It has been suggested that an increase 
in the atmospheric supply of iron $(\mathrm{Fe})$ by dust during glacial periods may have stimulated marine productivity in the Southern Ocean ( $\mathrm{SO}$ ), contributing to the reduction of atmospheric $\mathrm{CO}_{2}$ concentrations observed during ice ages (2). Dust-induced Fe fertilization represents one key mechanism that potentially affects past oceanatmosphere $\mathrm{CO}_{2}$ exchange (3-5), although the magnitude with respect to other $\mathrm{SO}$ processes such as sea-ice extent, overturning strength, and water column stratification is still under debate $(5,6)$. Antarctic ice cores allow only an indirect qualitative inference of dust deposition over the ocean and cannot be used to quantitatively estimate dust deposition in the different $\mathrm{SO}$ sectors. Marine sediments, however, provide a direct estimate of SO dust deposition and marine export production. To date, marine studies are primarily confined to the Atlantic SO sector located downstream of Patagonia, a strong dust source during glacial periods. In that region, substantially enhanced glacial dust fluxes and subantarctic productivity have been interpreted to control, at most, one-third to one-half of the observed glacial-interglacial atmospheric $\mathrm{CO}_{2}$ difference $(4,7)$, consistent with similar results based on the phasing of dust and $\mathrm{CO}_{2}$ fluctuations in the Epica Dome C (EDC) ice core (8). However, this finding is based on the assumption that dust deposition and Fe fertilization take place equally in the entire Subantarctic Zone. Biogeochemical models with geographically variable dust fields for the SO suggest a somewhat lower $\mathrm{CO}_{2}$ reduction (9).

Glacial dust recorded in ice cores from the East Antarctic Plateau originates almost exclusively from South America, including Patagonia (10). Model simulations (11) have supported this view and have suggested that dust deposition in the SO occurs mainly in the Atlantic and western Indian SO sectors. However, a recent simulation indicates that stronger glacial Australian dust sources resulted in a distinct glacial dust deposition field covering most of the Pacific SO sector but only reaching marginal areas of the Antarctic continent (12) (fig. S1). To date, sediment data on modern and glacial dust deposition in the Pacific SO are restricted to proximal sites around Australia, especially in the Tasman Sea (13) and subordinately east of New Zealand (14). These records show a substantial increase in the deposition of terrigenous material during the Last Glacial Maximum (LGM) compared with the present Holocene, but proximal

\footnotetext{
${ }^{1}$ Alfred-Wegener-Institut (AWI) Helmholtz-Zentrum für Polarund Meeresforschung, Bremerhaven, Germany. ${ }^{2}$ MARUM-Center for Marine Environmental Sciences, Bremen, Germany. ${ }^{3}$ LamontDoherty Earth Observatory, Columbia University, Palisades, NY 10964, USA. ${ }^{4}$ Department of Earth and Environmental Sciences, Columbia University, NY 10027, USA. ${ }^{5}$ Geologisches Institut, ETH Zürich, Zürich, Switzerland. ${ }^{6}$ Center for Climate and Resilience Research, University of Chile, Santiago, Chile. ${ }^{7}$ Geologie, Fachbereich Raum- und Umweltwissenschaften, Universität Trier, Trier, Germany.

*Corresponding author. E-mail: frank.lamy@awi.de
}

marine dust records are not necessarily representative of the pelagic Pacific SO. From the open Pacific Ocean, a number of short sediment records reveal enhanced lithogenic fluxes during the $\operatorname{LGM}(15,16)$. However, the contribution of dust remains inconclusive, because most of the coring sites are located in waters potentially affected by the deposition of ice-rafted detritus (IRD) (17).

Here, we report dust flux reconstructions over the past million years based on a suite of sediment cores across the western and central Pacific SO, recently collected during the German research vessel (R/V) Polarstern expedition ANT-XXVI/2 (18) (Fig. 1 and fig. S2). On the basis of benthic oxygen isotope stratigraphy and biostratigraphic age control points (19) (fig. S3), Fe-content changes in our sediment records reveal clear similarities to dust content variations documented in Antarctic ice cores and Atlantic SO sediments (fig. S4). We therefore aligned our high-resolution $\mathrm{Fe}$ content records to the EDC dust content record (1) back to $\sim 800$ thousand years before the present (ky B.P.) and to the Fe content record of Ocean Drilling Program (ODP) Site 1090 (7) for the interval extending beyond the reach of Antarctic ice cores (19). The similar pattern in the Fe and dust contents on glacial-interglacial time scales over the past million years in our Pacific SO sediment records (Fig. 2) extends from the Permanently Open Ocean and Polar Frontal Zone in the southern southwest Pacific Basin eastwards to the central Subantarctic Pacific (fig. S2). This geographic pattern largely follows the modeled modern Australian dust plume beneath the maximum westerly winds $(20,21)$ (Fig. 1) and also simulations of the LGM deposition pattern (12) (fig. S1) and is consistent with a primarily eolian origin of $\mathrm{Fe}$ supply to the Pacific SO. Though we cannot exclude minor input of IRD, the strong similarity between Fe content changes and the supply of terrestrial n-alkanes in two cores (fig. S5) strongly supports the predominant eolian origin. Moreover, IRD would not be distributed homogenously over large distances and thus would not create the consistent variations, as shown by our sediment records across the western and central Pacific SO (Fig. 2).

We selected two sediment cores from the suite of ANT-XXVI/2 cores to quantify mass accumulation rates of the lithogenic fraction $\left(\mathrm{MAR}_{\mathrm{Litho}}\right)$ and paleoproductivity estimates [biogenic barium $\left(\mathrm{Ba}_{\mathrm{exc}}\right)$ and opal (19)]. Core PS75/76-2 covers the past $\sim 1000 \mathrm{ky}$ and was recovered close to the Subantarctic Front in the southwest Pacific. Core PS75/59-2 reaches back to $\sim 480 \mathrm{ky}$ B.P. and is located in the Subantarctic Zone of the central South Pacific (Fig. 1 and fig. S2). MAR Litho $_{\text {were }}$ obtained by calibrating the high-resolution Fe content records with lithogenic contents calculated from the concentration of ${ }^{232} \mathrm{Th}$. As with the Fe content records, the shape and glacial-interglacial pattern of the Pacific SO MAR Litho records reveal

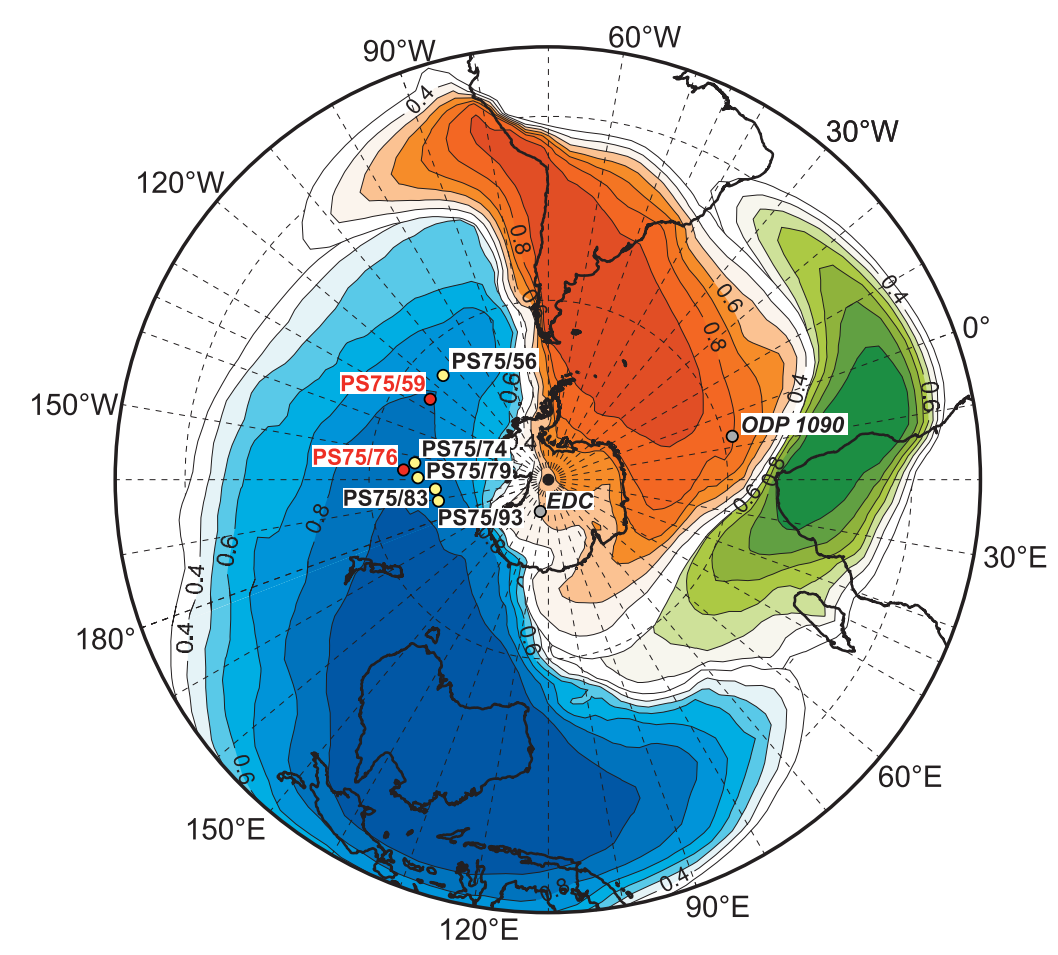

Fig. 1. Map showing the modern relative contributions of the three major dust sources in the Southern Hemisphere (blue, Australia; red, South America; green, South Africa), based on model data (20). Red dots mark primary core locations; yellow dots indicate additional cores; gray dots denote location of published reference records $(1,4,7)$. 
strong similarities to the EDC ice core dust MAR and Atlantic SO MAR Litho $_{\text {records from ODP Site }}$ 1090 (Fig. 3). Glacial MAR Litho $_{\text {are substantially }}$ higher and exceed interglacial values by a factor of $\sim 3$ to 15 (fig. S6).

However, fluxes of both biogenic and lithogenic material in the SO may be substantially affected by sediment focusing below the vigorous Antarctic Circumpolar Current (22). To correct vertical fluxes for the potential influence of lateral sediment redistribution (focusing), we applied the ${ }^{230} \mathrm{Th}$ normalization method [limited to the past $\sim 300$ ky B.P. (19)]. Glacial ${ }^{230} \mathrm{Th}_{\text {norm }}$ $\mathrm{MAR}_{\mathrm{Litho}}$ tend to be considerably lower than the non-normalized values (Fig. 3, B and C). For each site, the ${ }^{230} \mathrm{Th}$-normalized $\mathrm{MAR}_{\text {litho }}$ show internally consistent variability across the past three glacial-interglacial cycles, indicating $\mathrm{a} \sim$ threefold increase in lithogenic fluxes during glacials (Fig. 3E and fig. S6), comparable to glacial increases at low latitudes (23). The absolute ${ }^{230} \mathrm{Th}_{\text {norm }} \mathrm{MAR}_{\text {Litho }}$ values decrease from west $\left(156^{\circ} \mathrm{W}\right)$ to east $\left(125^{\circ} \mathrm{W}\right)$ (table $\left.\mathrm{S} 1\right)$. The downwind decrease of ${ }^{230} \mathrm{Th}_{\text {norm }} \mathrm{MAR}_{\mathrm{Litho}}$, recorded in our cores, is consistent with a primarily eolian source of the lithogenic material, originating from Australia, as also shown in dust simulations $(12,20)$. However, our interglacial

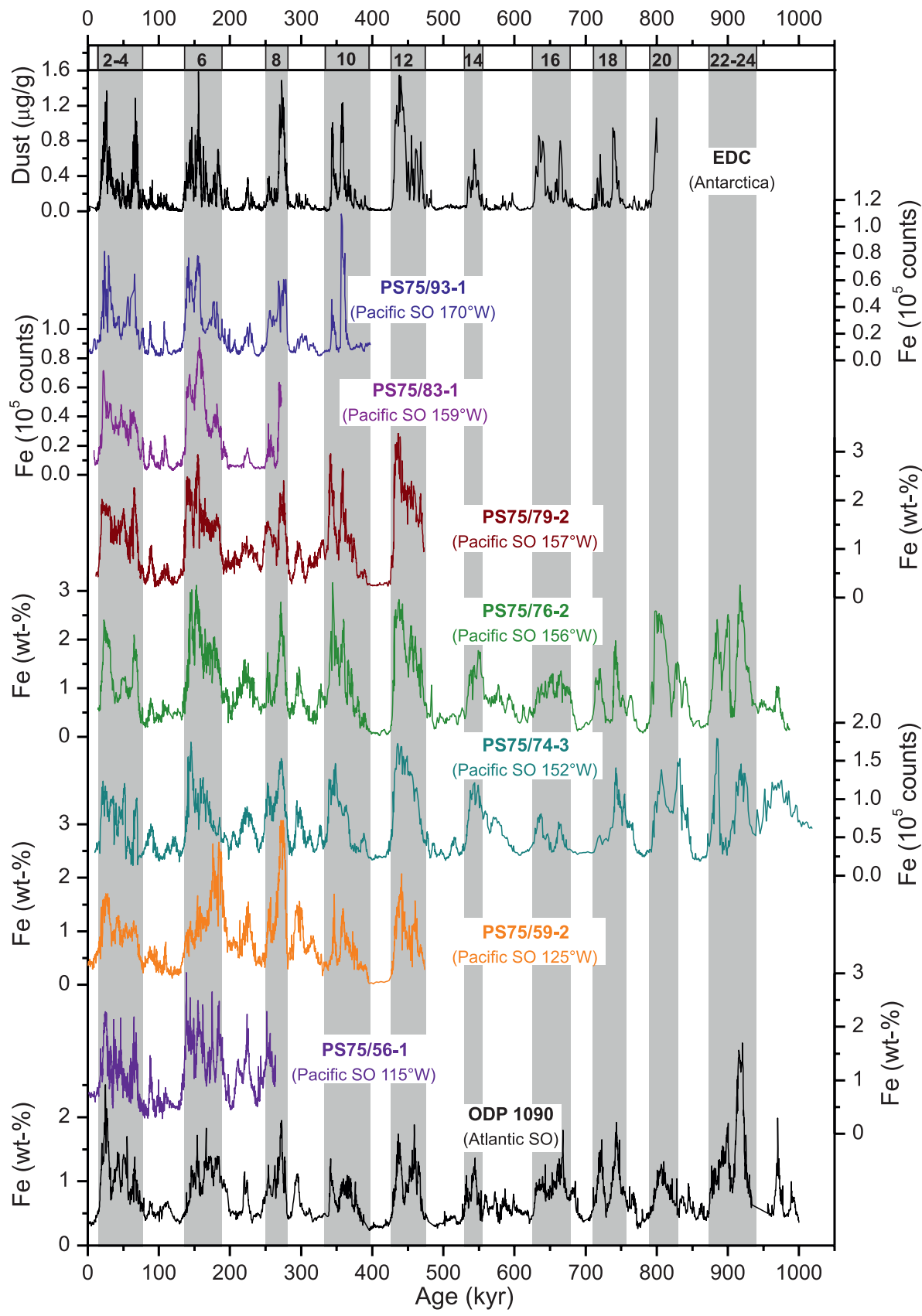

Fig. 2. Iron content fluctuations across the Pacific and Atlantic SO (7) compared to dust content changes in the EDC ice core (1).
${ }^{230} \mathrm{Th}_{\text {norm }} \mathrm{MAR}_{\text {Litho }}$ are somewhat higher than lithogenic particle fluxes from sediment traps and water samples in the southwest Pacific SO $(24,25)$ and model-based estimates for our core sites $(12,20)$. In contrast, higher Holocene Australian dust fluxes have been derived from New Zealand peat bogs (26) (table S1).

Our ${ }^{230} \mathrm{Th}_{\text {norm }} \mathrm{MAR}_{\text {Litho }}$ and ${ }^{230} \mathrm{Th}_{\text {norm }}$ n-alkane MAR records (Fig. 3, E and F) document a $\sim$ threefold increase of dust supply to the $\mathrm{Pa}$ cific SO during glacials (Fig. 3E and fig. S6), consistent with two previous ${ }^{230} \mathrm{Th}_{\text {norm }} \mathrm{MAR}_{\text {Litho }}$ records from the central Subantarctic Pacific SO (16) (Fig. 3E) and a compilation of other Pacific dust deposition records (27). Taken together, these sediment data suggest a considerable enhancement of glacial dust input to the Pacific SO. Though absolute Pacific glacial dust fluxes are $\sim 50 \%$ lower than in the Atlantic SO, the relative glacial-interglacial increase is almost as large. Considering the large geographic extension of the Pacific SO, this threefold increase in Pacific SO dust fluxes requires a substantial enhancement of the Australian dust source, considerable changes in atmospheric circulation, or an additional dust source not active during interglacials.

Modeling of the contribution of the different Southern Hemisphere dust sources to modern dust deposition in the SO shows that more than $80 \%$ of modern dust deposition in the western and central Pacific SO originates from Australia (12, 20) (Fig. 1). The large-scale distribution of Southern Hemisphere dust is primarily achieved through transport within the westerly wind belt. The uptake of dust and transport and distribution through the westerly wind belt into the SO primarily occurs in austral winter and spring (21), when the westerlies extend further north. In contrast to dust originating from Patagonia, Australian dust plumes are transported in the free troposphere and can thus be distributed over very large distances (20). Although there is presently no consensus about glacial changes of the westerlies in climate models (28), most paleodata-based reconstructions imply a strengthening and/or equatorward shift of the wind belt (27). Together with more expanded arid dust source areas in Australia (29) and increases in gustiness in the source regions (30), a northward extent and/or enhancement of the westerlies over southeast Australia during glacials would plausibly increase the dust uptake and export into the Pacific SO. Further, it is conceivable that New Zealand acted as an additional dust source. The westerlies, enhanced by strong katabatic winds in the lee of the glaciated New Zealand Alps (31), could have transported glacial outwash material out into the Pacific SO, a similar mechanism to that proposed for Patagonian dust sources (32). Distinguishing between an enhanced Australian dust source and the emergence of New Zealand as a glaciogenic dust source will require additional geochemical information about the provenance 
of the dust exported to the SO Pacific during glacial times.

The ${ }^{230}$ Th normalization method documents substantial sediment focusing at our two sites (fig. S7). Despite this effect of lateral sediment redistribution, the glacial-interglacial pattern and shape of dust fluctuations in the EDC ice core record are preserved in great detail [both in the MAR and Fe-content records (Figs. 2 and 3)]. This finding suggests that the climate-controlled variations in the availability of eolian material are the dominant factor in controlling the shape and pattern of glacial-interglacial lithogenic sediment accumulation, even at sites where focusing is substantial. A prominent feature of our PS75/76-2 MAR $_{\text {Litho }}$ beyond the range of ${ }^{230} \mathrm{Th}_{\text {norm }}$ is a decrease in glacial $\mathrm{MAR}_{\mathrm{Litho}}$ before marine isotope stage (MIS) 12 ( 480 ky B.P.) (Fig. 3B and fig. S6). A very similar decrease is likewise seen in the Fe content record from core PS75/74-3, excluding a local origin of this feature (Fig. 2). This change coincides with a less pronounced MidBrunhes shift in glacial-interglacial amplitudes in the EDC and ODP Site 1090 records (Fig. 3, A and $\mathrm{D}$, and fig. S6). Assuming that the shift in our $\mathrm{MAR}_{\mathrm{Litho}}$ is not entirely controlled by a systematic change in sediment focusing through bottom currents during the Mid-Brunhes interval, our data document reduced glacial dust input for the pre-MIS 11 interval. One explanation could be a different sensitivity of the Australian dust sources to glacial severity. In contrast to Patagonia, which lies at higher latitudes, Australian dust sources may require colder global temperature to achieve a similar increase to their Patagonian counterparts. Pre-MIS12 glacials were generally shorter than younger ones (1). Therefore, the time of high dust productivity may have been much shorter for Australian and New Zealand dust sources compared to Patagonian sources, explaining the more substantial decrease in pre-MIS 12 glacial Pacific dust fluxes.

Taken together, our sediment records document a substantial glacial dust supply from Australian and/or New Zealand sources to the Pacific SO sector eastward to at least $125^{\circ} \mathrm{W}$. The $\sim$ threefold increase in glacial dust accumulation in the $\mathrm{Pa}$ cific SO confirms the enhanced LGM-Holocene dust flux ratios from simulations (12) (fig. S1). Our Pacific SO data revise the current picture of Patagonia representing the almost exclusive source region for glacial dust deposited in the glacial SO. The previously unmeasured dust input to the largest SO sector during several glacial periods may have substantial implications for biological productivity on a global scale. Preliminary paleoproductivity estimates based on $\mathrm{Ba}_{\mathrm{exc}}$ and biogenic opal records from our subantarctic core PS75/59-2 suggest two to three times higher glacial values; that is, the same order of magnitude as the dust increase (Fig. 4). This finding is consistent with other available sediment records from the Pacific SO $(15,16)$ that reveal generally higher opal MAR north of the modern Antarctic Polar Front during glacials. However, these data

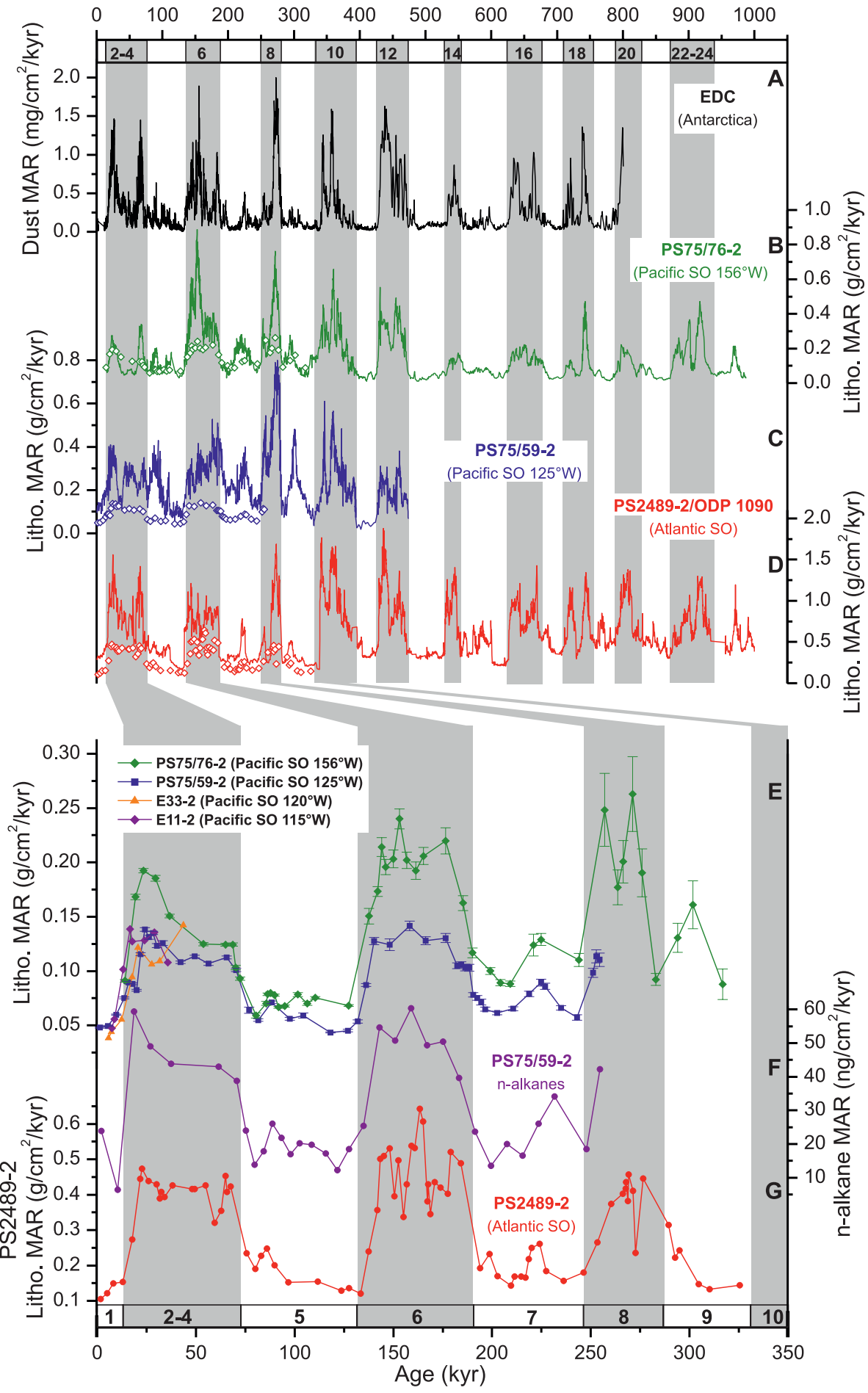

Fig. 3. Changes in lithogenic mass accumulation rates $\left(M A R_{L i t h o}\right)$. (A) Dust MAR in the EDC ice core (1). (B) MAR Litho $_{\text {core PS75/76-2. (C) MAR }}$ Litho core PS75/59-2. (D) MAR Litho ODP Site $1090(4,7)$ [recalculated (19)]. Open diamonds in (A) to (C) show ${ }^{230}$ Th-normalized MAR $\mathrm{L}_{\text {itho. }}$ (E) ${ }^{230}$ Th-normalized MAR $_{\text {Litho }}$ values from cores PS75/59-2, PS75/76-2, E11-2, and E33-2 (16). (F) ${ }^{230}$ Th-normalized $C_{29}$ and $C_{31}$

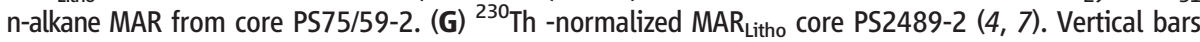
in $(\mathrm{E})$ denote $1 \sigma$ error.

also indicate that this increase is compensated by decreasing productivity southward, a pattern that has been suggested to extend across multiple glacial-interglacial cycles in the Atlantic SO (33).
Furthermore, opal MAR do not necessarily reflect productivity of the surface ocean and enhanced organic carbon export, particularly in the seasonal ice zone (3). 


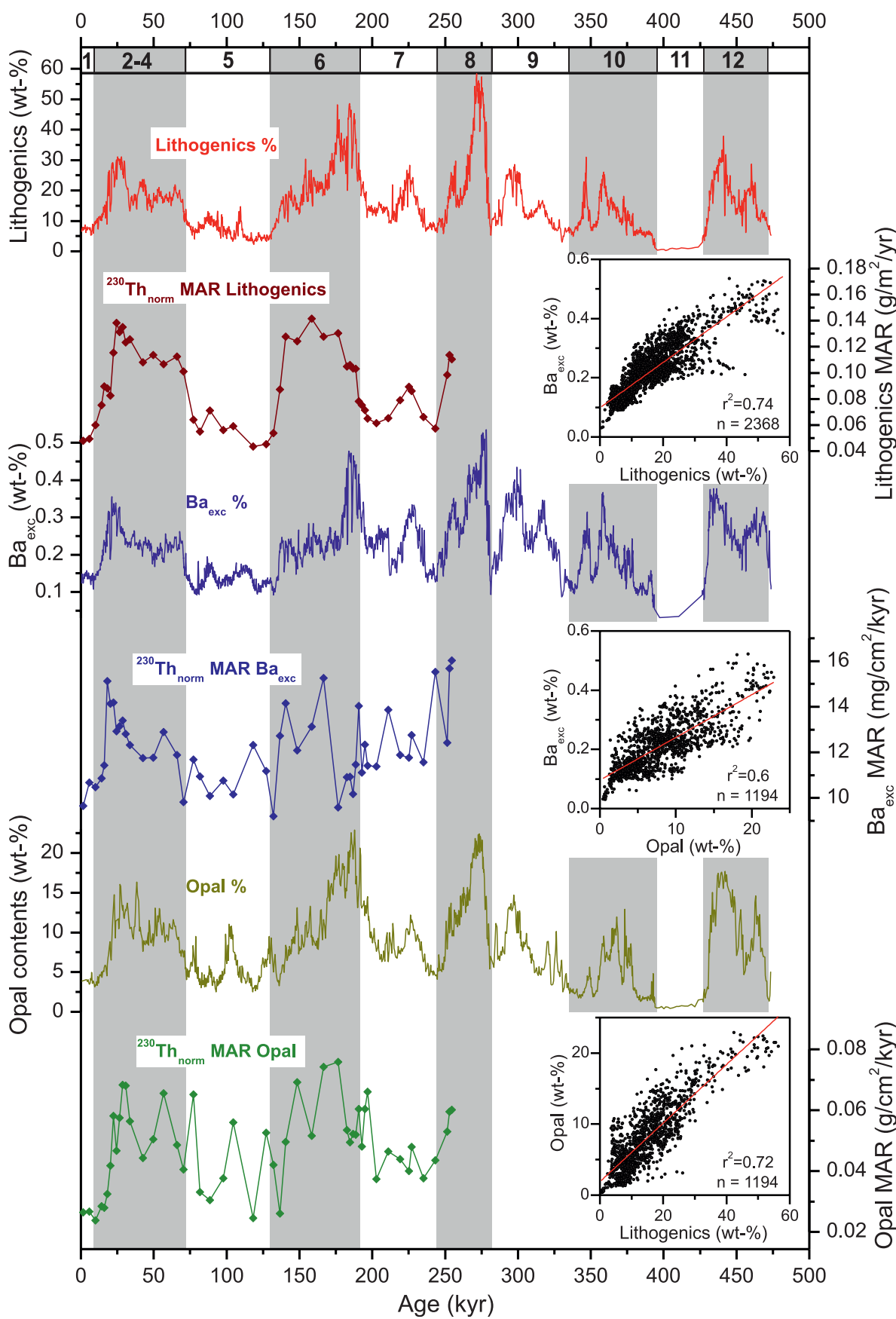

Fig. 4. Proxy records for paleoproductivity from subantarctic core PS75/59-2. Together with their contents, the ${ }^{230}$ Th-normalized MAR records of $\mathrm{Ba}_{\mathrm{exc}}$, biogenic opal, and lithogenics are shown. Scatter diagrams (insets) show positive correlation between lithogenics, $\mathrm{Ba}_{\mathrm{exc}}$ and biogenic opal, suggesting that the paleoproductivity and lithogenic supply records largely covary. $r^{2}$, correlation coefficient; $\mathrm{n}$, number of samples.

\section{References and Notes}

1. F. Lambert et al., Nature 452, 616-619 (2008). 2. J. H. Martin, Paleoceanography 5, 1-13 (1990).

3. A. Abelmann, R. Gersonde, G. Cortese, G. Kuhn,

V. Smetacek, Paleoceanography 21, PA1013 (2006).

4. A. Martínez-Garcia et al., Paleoceanography 24, PA1207 (2009).

5. D. M. Sigman, M. P. Hain, G. H. Haug, Nature 466 , 47-55 (2010).

6. H. Fischer et al., Quat. Sci. Rev. 29, 193-205 (2010).
7. A. Martínez-Garcia et al., Nature 476, 312-315 (2011).

8. F. Lambert, M. Bigler, J. P. Steffensen, M. Hutterli, H. Fischer, Clim Past 8, 609-623 (2012).

9. L. Bopp, K. E. Kohfeld, C. Le Quere, O. Aumont, Paleoceanography 18, PA1046 (2003).

10. D. M. Gaiero, Geophys. Res. Lett. 34, L17707 (2007).

11. N. M. Mahowald et al., J. Geophys. Res. Atmos. $\mathbf{1 1 1}$ D10202 (2006).

12. S. Albani, N. M. Mahowald, B. Delmonte, V. Maggi, G. Winckler, Clim. Dyn. 38, 1731-1755 (2012).
13. P. P. Hesse, G. H. McTainsh, Quat. Res. 52, 343-349 (1999).

14. J. Thiede, Geology 7, 259-262 (1979).

15. L. I. Bradtmiller, R. F. Anderson, M. Q. Fleisher, L. H. Burckle, Paleoceanography 24, PA2214 (2009).

16. Z. Chase, R. F. Anderson, M. Q. Fleisher, P. W. Kubik, Deep-Sea Res. Part // 50, 799-832 (2003).

17. ]. Tournadre, F. Girard-Ardhuin, B. Legresy, J. Geophys Res. Oceans 117, C05004 (2012).

18. R. Gersonde, The Expedition of the Research Vessel "Polarstern" to the Polar South Pacific in 2009/2010 (ANT-XXVI/2 - BIPOMAC) (Alfred Wegener Institute for Polar and Marine Research, Bremerhaven, Germany, 2011).

19. Materials and methods are available as supplementary materials on Science Online.

20. F. Li, P. Ginoux, V. Ramaswamy, J. Geophys. Res. Atmos. 113, D10207 (2008).

21. H. McGowan, A. Clark, Atmos. Environ. 42, 6915-6925 (2008).

22. T. L. Noble et al., Earth Planet. Sci. Lett. 317-318, 374-385 (2012).

23. G. Winckler, R. F. Anderson, M. Q. Fleisher, D. McGee, N. Mahowald, Science 320, 93-96 (2008).

24. C. I. Measures, S. Vink, Global Biogeochem. Cycles 14, 317-327 (2000).

25. F. L. Sayles, W. R. Martin, Z. Chase, R. F. Anderson, Deep-Sea Res. Part II 48, 4323-4383 (2001).

26. S. K. Marx, B. S. Kamber, H. A. McGowan, ]. Denholm, Geochim. Cosmochim. Acta 73, A843 (2009).

27. K. E. Kohfeld et al., Quat. Sci. Rev. 68, 76-95 (2013).

28. L. C. Sime et al., Quat. Sci. Rev. 64, 104-120 (2013).

29. P. P. Hesse, G. H. McTainsh, Quat. Sci. Rev. 22, 2007-2035 (2003)

30. D. McGee, W. S. Broecker, G. Winckler, Quat. Sci. Rev. 29, 2340-2350 (2010).

31. B. V. Alloway et al., J. Quaternary Sci. 22, 9-35 (2007).

32. D. E. Sugden, R. D. McCulloch, A. J. M. Bory, A. S. Hein Nat. Geosci. 2, 281-285 (2009).

33. S. L. Jaccard et al., Science 339, 1419-1423 (2013).

Acknowledgments: We thank the captain, crew, and scientific party of R/V Polarstern for their support during cruise ANT-XXVI-2. ]. Collins, R. Tiedemann, H. W. Arz, and three anonymous reviewers provided comments and suggestions that substantially improved the paper. We acknowledge data contributions by P. Köhler and S. Steph and thank S. Albani and N. Mahowald for making their model output available. U. Bock, J. Hefter R. Fröhlking, and S. Wiebe provided technical support at AWI. G.W. thanks R. Schwarz and M. Q. Fleisher for excellent laboratory support at Lamont-Doherty Earth Observatory. We acknowledge financial support for this work through the AWI Helmholtz-Zentrum für Polar- und Meeresforschung, the MARUM-Center for Marine Environmental Sciences, the University of Bremen, and the European Union project Past4future. F. Lambert acknowledges support by Project CONICYT/FONDAP/15110009. Data are available at www.pangaea.de.

\section{Supplementary Materials}

www.sciencemag.org/content/343/6169/403/suppl/DC1

Materials and Methods

Figs. $\mathrm{S} 1$ to $\mathrm{S} 10$

Table S1

References (34-58)

2 September 2013; accepted 19 December 2013 10.1126/science. 1245424 